\title{
USO DE PSICOATIVOS ENQUANTO HÁBITO DE SOCIABILIDADE: OBSERVAÇÕES SOBRE AS RUAS DA CIDADE BAIXA (PORTO ALEGRE/RS)
}

Jardel Fischer Loeck ${ }^{1}$

\section{Introdução}

Normalmente nas abordagens atuais da grande mídia, que inevitavelmente se espalham pelo senso comum, quando se fala do uso de substâncias psicoativas ilícitas a referência é sempre negativa. Tanto pelo fato de se tratar de práticas ilegais quanto pela possibilidade de desenvolvimento da "dependência química" - uma doença associada diretamente ao uso de substâncias psicoativas, lícitas e ilícitas. Qualquer tipo de uso destas substâncias passa a ser negativado, como se não existisse potencial criativo ou positivo por trás dos mesmos, como se toda e qualquer prática de uso fosse por si só doentia. A “dependência química” é, desta forma, um dos pilares que sustenta os discursos negativos sobre as práticas de uso de psicoativos ilícitos. Mas as estatísticas, por mais contestáveis e subnotificadas que possam ser, demonstram que os maiores índices de dependência estão relacionados ao uso de álcool e tabaco (substâncias lícitas) e que os números referentes à dependência das substâncias ilícitas são, no geral, bastante baixos (Carlini, 2006).

De qualquer forma, é sabido que a proibição não impede que essas substâncias circulem e sejam consumidas de formas diversas, principalmente nos meios urbanos, tanto de maneiras problemáticas quanto não problemáticas. Temos os usos rituais e/ou religiosos (ayahuasca no Brasil, peyote no México e EUA), usos terapêuticos (medicamentos psicotrópicos) - ambos regulamentados por lei-, mas também temos usos lúdicos, recreativos, com fins de entorpecimento, de alteração da consciência, que podem acontecer em situações de sociabilidade e de interação. Nestes casos, de usos com fins recreativos, o leque de opções engloba muitos tipos de substâncias, lícitas e ilícitas, desde álcool e medicamentos psicotrópicos até lsd, ecstasy, maconha, cocaína e crack. As práticas que contém o elemento da ilegalidade muitas vezes são invisíveis para grande parte da sociedade, principalmente nos casos em que os indivíduos não desenvolvem problemas de qualquer ordem relacionados a elas.

A diferenciação jurídica entre substâncias lícitas e ilícitas não impede que se proponha entender todos os usos de substâncias psicoativas com fins de entorpecimento a partir de uma mesma categoria, enquanto uma prática similar. Mas é fato que existem particularidades a respeito do uso de cada uma delas, relacionadas tanto a aspectos físico-psico-biológicos - pois cada

\footnotetext{
${ }^{1}$ Universidade Federal do Rio Grande do Sul, Brasil.
} 
substância age de uma maneira específica na interação com um organismo humano particular -, quanto a aspectos sociológicos e culturais. Em outras palavras, os circuitos pelos quais circulam e são comercializadas as diferentes substâncias psicoativas não são necessariamente os mesmos, pensando na delimitação geográfica de uma grande cidade como Porto Alegre. Também os locais onde são consumidas essas diferentes substâncias não são necessariamente os mesmos, embora devam existir, neste sentido, alguns espaços mais democráticos que outros.

A publicitação do uso de substâncias ilícitas é fator estigmatizante, nos termos de Goffman (1975), fato que muitas vezes impulsiona os usuários a criar estratégias no sentido de manipular sua identidade e suas práticas em determinadas situações ou em alguns ambientes. Mas de alguma forma, em algum lugar, essas pessoas executam suas práticas, mantêm seus hábitos. Talvez muitas dessas pessoas possam mantê-las em ambientes particulares, domésticos, mas existem indícios de que alguns espaços públicos ou semi-públicos no interior das grandes cidades em determinados horários são dotados de uma lógica própria no que diz respeito à tolerância da embriaguez, e mesmo do uso de substâncias psicoativas ilícitas. Estou me referindo especialmente às práticas de sociabilidade na vida noturna de bairros notadamente boêmios de grandes capitais, como parte da Rua Augusta, em São Paulo, a Lapa, no Rio de Janeiro, ou a Cidade Baixa, em Porto Alegre.

Assim, neste artigo, em primeiro lugar aponto para a possibilidade de definir as práticas de uso das substâncias psicoativas ilícitas a partir de um referencial positivo, ou ao menos não negativado de antemão, relacionando-as a práticas de sociabilidade, tal qual Simmel as definiu, e também a partir da ideia de hábito desenvolvida por Bachelard, contrapondo estas à negatividade da "dependência química" entendida como uma doença. Em um segundo momento apresento algumas reflexões iniciais a respeito de um circuito específico no qual são consumidas algumas dessas substâncias, e também no qual o uso das mesmas é, de certa forma, facilmente observado principalmente no período noturno: o bairro Cidade Baixa, na cidade de Porto Alegre/RS.

\section{Dependência Química X Uso de Psicoativos: Doença X Hábito de Sociabilidade}

A “dependência química" enquanto doença está diretamente associada a práticas de uso de substâncias psicoativas, no sentido de que só pode se manifestar em pessoas que praticam estas atividades. Mas as práticas de manipulação da subjetividade através do uso de substâncias psicoativas são recorrentes através da história humana em épocas, locais e contextos bastante específicos, contemplando usos tradicionais ou rituais, medicamentosos e mesmo recreativos, além dos usos doentios identificados pelas ciências biomédicas na contemporaneidade. Em outras palavras, falar de uso de psicoativos é usar um termo generalizante para falar de uma infinidade de práticas, cada uma delas materializada na conjunção dos fatores substância, indivíduo e contexto 
sociocultural.

Com o desenvolvimento dos grandes conglomerados urbanos muitas dessas práticas outrora tradicionais, ritualizadas, se inserem em uma nova dinâmica, mais fugidia e supostamente individualizada, e se tornam motivo de intervenção, tanto por parte das políticas governamentais quanto das ciências, principalmente daquelas que têm como objeto o corpo e a saúde humana. No mundo contemporâneo grande parte das substâncias conhecidas é de uso controlado (medicamentoso) ou restrito (substâncias proibidas), proporcionando a formação de uma espécie de rede de controlelassistência ${ }^{2}$ que captura muitos desses usuários e os denomina transgressores ou doentes.

De acordo com dados históricos (Carneiro, 2002; 2005), foi no final do séc. XIX que primeiramente o consumo nocivo do álcool foi visto como uma doença e, posteriormente, no primeiro quarto do séc. XX essa ideia foi estendida para outras substâncias psicoativas. Mas pelo fato de muitas das substâncias consumidas serem ilegais há um entrecruzamento com a esfera jurídica, o que acaba por borrar os limites entre uso problemático e uso não problemático. Como argumenta Stengers (1997), no caso do uso de psicoativos ilícitos atua um "consenso moral” que define qualquer uso das substâncias como problemático e passível de intervenção, pois a transgressão à lei é vista como um indicativo de problemas individuais e necessidade de ajuda.

De qualquer forma, alguns estudos dentro das Ciências Sociais, hoje considerados pioneiros no trato do assunto ${ }^{3}$, demonstram que mesmo no caso das substâncias ilícitas existem modalidades de consumo não doentio ou dotadas de significação, em oposição à situação de "dependência química". Outros autores contemporâneos vem se engajando em tentar defini-las a partir de uma visão menos contaminada pela interpretação biomédica ou legalista.

Como Carneiro (2008: 77), que relaciona o uso de psicoativos a uma "crescente plasticidade da subjetividade humana que se espelha em diversos meios técnicos para buscar a alteração de si, dos estados de consciência, cognição, afetividade e humor”. Nesta esteira, junto com o uso de psicoativos, o autor considera outras formas de alteração da consciência por meios técnicos na atualidade, como a televisão, a realidade virtual e os meios de comunicação eletrônicos, e coloca no centro deste debate a questão da autonomia e da heteronomia na gestão dessas práticas. Assim,

\footnotetext{
${ }^{2}$ Os componentes dessa rede seriam, a meu ver, o aparato jurídico/policial que regula o consumo de psicoativos, as terapias biomédicas e psicológicas para a "dependência", e também as "terapias alternativas" para o mesmo problema. Vargas afirma ser possível pensar em um tipo de dispositivo das drogas, da mesma maneira que Foucault (1982) pensou no dispositivo da sexualidade. Isso porque durante o século XX ocorreu um processo de "invasão farmacêutica" ilustrada pela implementação do uso de diversos medicamentos psicotrópicos na medicina moderna concomitantemente ao processo de proibição do uso da grande maioria das substâncias psicoativas não medicamentosas (VARGAS, 2008: 55). Ou seja, pensando nas substâncias psicoativas como uma categoria ampla, o seu consumo é ao mesmo tempo incitado e reprimido, desde meados do séc. XX.

${ }^{3}$ Penso principalmente nos trabalhos de Velho (1998), Becker (1973), MacRae \& Simões (2000), entre outros.
} 
Carneiro (2008: 76) considera que na contemporaneidade existe um grande aumento das potencialidades do "exercício autonômico sobre si" - materializados nas técnicas de alteração da consciência - e, paradoxalmente, "uma perda da capacidade de julgar e agir por si próprio" - que, no caso do uso de psicoativos, se materializa no fato de que as substâncias que podem ser consumidas dependem de prescrição médica - com exceção do álcool.

Ou então Vargas (2008), que a partir de Paracelso diz que "tal exploração propõe que as drogas sejam consideradas como uma categoria complexa e polissêmica que recobre e reúne (...) matérias moleculares as mais variadas" (p.41). Além disso, o mesmo autor considera essas matérias moleculares objetos sócio-técnicos que comportam diferenças apenas no âmbito relacional e nunca absoluta ou essencialmente. E, junto com Deleuze e Guatarri, Vargas (2008: 41) também diz que como as armas, esses objetos sócio-técnicos permanecem indeterminados "até que sejam reportados aos agenciamentos que os constituem enquanto tais". Ou seja, se existe algum tipo de problema relacionado a essas práticas ele reside exatamente nos agenciamentos que se configuram com ou a partir das substâncias, e não nestas per se.

Em outro texto o mesmo autor aponta para a ocorrência de "eventos", identificados pelo termo "onda", durante as práticas de uso de psicoativos. Para Vargas (2006: 584) estas práticas constituem "modos singulares de engajamento no mundo, nos quais as substâncias são mediadoras indispensáveis para a produção de alter-ações". O autor considera que esses modos de engajamento no mundo seriam pautados por outro tipo de interpretação da vida, não mais considerada em "extensão" - como na prerrogativa do ideal biomédico de prorrogar a vida a qualquer custo -, mas em "intensidade" (Vargas, 2006).

O que muitas vezes se ouve a respeito dessas práticas quando realizadas no mundo urbano contemporâneo é que não são ritualizadas, que são práticas hedonísticas, que visam a satisfação pessoal e individual, o prazer físico e subjetivo. Ou que a repetição do uso e o desenvolvimento de hábitos de consumo as tornariam insignificantes socialmente, mera resposta a demandas físicas, orgânicas. Mas a ideia neste artigo é exatamente tentar desconstruir a negatividade ou individualidade atribuída ao hábito de consumo de psicoativos, apontando para a existência de hábitos de sociabilidade que são mediados pelo uso destas substâncias.

É com o auxílio de Gaston Bachelard (1965) que procuro fazer esta guinada interpretativa, principalmente a partir de sua noção de "hábito". No livro "A intuição do instante" este autor nos apresenta, a partir de uma síntese crítica do pensamento bergsoniano sobre o tempo e sobre a duração, articulada às ideias do historiador francês Roupnel, a noção de tempo enquanto descontínuo, formado por uma sucessão de "instantes". Do conjunto dessa obra a parte que mais inspira o desenvolvimento deste argumento é o segundo capítulo, no qual Bachelard problematiza e 
tensiona as possibilidades de formação de hábitos no âmbito da prevalência dos instantes e do tempo descontínuo. Segundo o autor os instantes são necessariamente criativos ou dotados de potência criativa, diferentemente da duração de Bergson (1988), que trata sempre de um passado mais contraído ou mais distendido.

O que interessa, então, é a noção de hábito enquanto maneira de permanecer no tempo, enquanto forma de um indivíduo se auto-identificar no decorrer desse tempo descontínuo. E o mais importante nesta noção é a continuidade da criação e da inovação que persiste na repetição dos atos que formam os hábitos. Bachelard diz que o hábito pode ser entendido como uma espécie de síntese entre a novidade e a rotina, e que o hábito seria um tipo de "assimilação rotinizada da novidade". Ou seja, aquilo que é humano é fruto dos instantes criativos. E estes não são necessariamente apreendidos individualmente, mas também de forma compartilhada através da co-presença. Neste mundo emergente, em que a significação da realidade é construída em ato, um costume ou hábito como o uso socializado de substâncias psicoativas pode ser fator importante na construção da identidade de alguns indivíduos.

E, se como diz o autor que "é pelo ritmo que se pode compreender melhor tal continuidade do descontínuo", e que "o ser continua pelo hábito, como o tempo dura pela densidade regular dos instantes da duração" (Bachelard, 1965: 68) ${ }^{4}$, pode ser que na rítmica da recorrência das práticas de uso de psicoativos possamos ter um indicativo interessante sobre a diferenciação entre usos problemáticos e não problemáticos. Enquanto a repetição do hábito realmente proporcionar instantes de criação e compartilhamento de experiências, ao invés de um uso individualizado e inerte, talvez tenhamos exemplos de bons usos de psicoativos, mesmo daqueles ilícitos.

Mas, como tentarei demonstrar na segunda parte do artigo, esses ritmos compartilhados, esses instantes criativos que não são individuais estão diretamente relacionados a uma temporalidade e uma demarcação do espaço urbanas, da cidade, na medida em que as práticas ilícitas demandam espaços sociais nos quais as normas são diferentes daquelas que a letra das leis procura impor e as práticas lícitas são regidas por regras morais de conduta que impõem momentos e espaços específicos às práticas de entorpecimento.

Outro indicativo que pode ser útil à diferenciação entre uso problemático e não problemático de psicoativos diz respeito ao compartilhamento ou não desses hábitos, da prática individual ou socializada das mesmas. Pensando a partir dos termos propostos acima, pode-se facilmente pensar em práticas de sociabilidade que girem ao redor do uso de alguma(s) substância(s) psicoativa(s). A já citada tese de doutorado de Gilberto Velho (1998) é um exemplo, com o retrato de um grupo de

\footnotetext{
${ }^{4}$ Tradução minha.
} 
classe média alta, integrados socialmente, consumindo maconha, álcool e cocaína em situações de sociabilidade, como eventos sociais, festas, ou reuniões em grupo; além disso, apresenta um grupo de jovens surfistas consumidores de maconha. Pode-se citar também o trabalho de Becker (1973) sobre o aprendizado que envolve o tornar-se um usuário de maconha. Ou então Fernandez (2007), que demonstra esses aspectos relacionados a usuários de cocaína na cidade de São Paulo, abordando tanto padrões de uso problemático quanto padrões de uso recreativo entre pessoas socialmente integradas, que não se envolvem em problemas relacionados ao uso da substância. Seu trabalho aponta para os rituais de uso, os ambientes e as maneiras de consumir cocaína em grupos sociais diversos, os controles sociais introduzidos por estes grupos, entre outros assuntos.

Como propõe Simmel (1983), a interação social ou sociabilidade pode ser mediada por um sem fim de situações e agenciamentos humanos, mas ela parece ser um fim em si mesma. São exatamente esses momentos de face a face que permitem o estabelecimento da sociedade, a construção da cultura, segundo esse autor. Nas suas palavras: "As verdadeiras motivações da sociação, condicionadas pela vida, não tem importância para a sociabilidade (...) Pois a forma é a mútua determinação e interação dos elementos da associação. É através da forma que constituem uma unidade" (1983: 169). Em outro trecho ele diz que "a sociabilidade, se se quiser, cria um mundo sociológico ideal, no qual o prazer de um indivíduo está intimamente ligado ao prazer dos outros" (1983: 173). Ou então que "seu alvo não é nada além do sucesso do momento sociável, quando muito, da lembrança dele" (1983: 170). Para finalizar, ele ainda diz que "a sociabilidade é o jogo no qual se 'faz de conta' que são todos iguais e, ao mesmo tempo, se faz de conta que cada um é reverenciado em particular" (1983: 173). Ou seja, as pessoas sociabilizam, se sociam, quase que por um instinto natural, por motivos muito diversos. Acredito que interpretar o uso recreativo de substâncias psicoativas enquanto práticas de sociabilidade, independentemente do caráter legal ou ilegal da substância, seja um instrumento interessante para se pensar a sociedade urbanocontemporânea.

Simmel, ao partir da capacidade do indivíduo moderno em criar e estabelecer relações propõe que o sujeito psíquico seja o desencadeador de ações, e também que o mundo social se funda a partir dele. O seu interesse é, exatamente, descobrir como se configuram as formas da vida social, como esses indivíduos autônomos se agrupam, como formam a sociedade e cultivam, criam constantemente, ininterruptamente, a cultura, na dialética entre uma cultura objetiva e uma cultura subjetiva. A sociedade, para ele, só pode existir a partir das formas de sociação, da formação de interações regulares entre indivíduos. Assim, pensar nas práticas de uso de psicoativos enquanto fatores ou mediadores de sociabilidade é pensar em agrupamentos de indivíduos, não em práticas individualizadas. E essas práticas de sociabilidade, de certa forma públicas ou semi-públicas - no 
mínimo compartilhadas com alguns pares -, estão ligadas aos ritmos da cidade em sua constituição multifacetada, com grandes fluxos de pessoas e objetos, com redes de comércio e de relações que permeiam a visibilidade e a invisibilidade, com trânsitos legais e ilegais de igual intensidade. A vida na cidade, portanto, e não apenas neste sentido binário legal/ilegal, é composta por uma superposição de vários mundos, de vários territórios, tanto geográficos quanto de sentido. Como sugerem Eckert \& Rocha,

\begin{abstract}
A vida metropolitana, apreendida no contexto do pensamento simmeliano, revela-se como ponto de interseção de vários mundos, isto é, 'uma continuidade não-regularizada de formações, informações e deformações de conteúdos novos e antigos que se individualizam nas formas que os animam, de tal modo que no desenvolvimento vital aquilo o que é cada vez formado ultrapassa a forma momentaneamente adotada'. Formas estas dadas pela diversidade de combinações das afiliações dos indivíduos aos grupos, em que as interações estão sujeitas ao espírito da vida moderna. (2001: 3)
\end{abstract}

Segundo as autoras, ao se estudar as culturas contemporâneas, indissociavelmente ligadas aos ritmos das cidades, deve-se levar em consideração as dinâmicas múltiplas que estão em jogo, as diferentes representações mentais que compõem a paisagem urbana, em suas muitas "regiões morais" e "províncias de significado". Para atingir tal meta a sugestão é de que sigamos "o deslocamento dos grupos/indivíduos entre as "províncias' e 'territórios de significação nas cidades"” (Eckert \& Rocha, 2001: 4). Nas suas próprias palavras:

É através do estudo dos itinerários urbanos e das formas de sociabilidade, das intrigas e dos dramas que configuram o teatro da vida citadina, apreendidos como uma espécie de mapeamento simbólico do movimento da vida que se pode, nos dias de hoje, refletir sobre a complexidade sociológica das estruturas espaço-temporais sob as quais se assentam os fenômenos da alteridade e da experiência humana no mundo contemporâneo.

(Eckert \& Rocha, 2001: 4)

Assim, um elemento desse tipo de sociabilidade entorpecida que pretendo chamar a atenção em seguida, através de exemplos trazidos de algumas observações empíricas, é o espaço físico urbano, os territórios nos quais são colocadas em ação essas práticas de sociabilidade bastante peculiares. Os indivíduos consumidores de psicoativos movimentam-se, deslocam-se dentro das cidades em suas práticas, tanto obtendo as substâncias e as consumindo quanto socializando sob o efeito das mesmas.

Desta forma, acredito ser interessante partir de um recorte urbano de regiões que agreguem um conjunto de bares e casas noturnas, ou de estabelecimentos que comercializem bebidas alcoólicas, que recebam grupos de pessoas com o propósito de se embriagar. Dentro das cidades as regiões com grande concentração de bares e casas noturnas, regiões nas quais o ato de estar embriagado é permitido socialmente, parecem formar espaços urbanos com lógicas próprias. Ao 
menos no período noturno quando esses estabelecimentos estão mais ativos. A seguir apresento algumas reflexões sobre esta questão dentro do contexto de um bairro boêmio da cidade de Porto Alegre, demonstrando como no interior do próprio bairro existem regiões nas quais algumas práticas são implícita ou explicitamente mais permitidas do que em outras.

\section{Sociabilidade entorpecida nas ruas da Cidade Baixa: observações iniciais sobre o consumo de psicoativos em um espaço urbano}

Essa repetição de instantes criativos que pode ser o hábito de consumir substâncias psicoativas, em muitos casos é uma experiência compartilhada com outros indivíduos, é um hábito de sociabilidade, em situações de clara ruptura com o tempo cotidiano do dia, do trabalho. É este o tipo de prática de consumo de psicoativos que estou tentando focar neste artigo. Se observarmos alguns espaços nas cidades, alguns recortes dentro dos centros urbanos - como o bairro Cidade Baixa, em Porto Alegre -, parece que estes giram em torno dessas práticas, principalmente do consumo de álcool. Pensando principalmente nas grandes cidades, são espaços cuja vida noturna, com sua infinidade de opções de bares, restaurantes e boates, criam todo um universo humano e social próprio durante alguns períodos. E em alguns casos, é importante ressaltar, essas "regiões morais", essas "províncias de significados", não se restringem aos espaços privados, ao interior dos estabelecimentos, mas também à própria rua enquanto espaço de circulação, sociabilidade e consumo.

O bairro Cidade Baixa, por se situar ao lado do centro de Porto Alegre, passou por inúmeras transformações ao longo dos anos. De abrigo de escravos libertos a bairro popular e depois de classe média, um dos aspectos que parece ter persistido nessa região foi sua inclinação à boemia, como aponta Jardim em sua dissertação sobre sociabilidades masculinas em bares da Cidade Baixa:

\footnotetext{
Entre os usos que foram feitos do bairro são exatamente as atividades lúdicas que se destacam como referência do seu passado, onde o carnaval e a boemia são os elementos recorrentes. Também entre meus informantes havia uma referência constante ao carnaval e à boemia como eventos significativos do passado recente do bairro.

(Jardim, 2006: 63)
}

O trabalho da antropóloga, realizado no começo da década de 1990, recebeu no ano de 2006 um posfácio, no qual ela reflete sobre algumas transformações recentes ocorridas no bairro, e que são úteis para ilustrar a caracterização atual do bairro que tento apresentar, enquanto um espaço de sociabilidade da boemia. Nas suas palavras:

De lá para cá, é impossível não deixar de comentar as mudanças de feições do bairro em que centrei minha pesquisa empírica. Cabe ressaltar que a Cidade Baixa de 2006 é, atualmente, um 
lugar de enorme concentração de bares e intensa vida noturna para uma juventude, não exclusivamente de camadas médias (...) Atualmente, as mesas nas calçadas, bares e cafeterias, ou restaurantes de camadas médias são bem mais visíveis do que os botecos de 1991 .

(Jardim, 2006: 11)

É esta configuração que encontramos hoje, de uma grande intensidade noturna e que abriga pessoas de diversas camadas sociais, assim como grupos cuja identificação se dá a partir de referenciais culturais e sociais também diversos. Há desde estabelecimentos com preços populares a casas noturnas não tão acessíveis. Obviamente que esta região não é a única opção de boemia na cidade de Porto Alegre. Poderíamos identificar várias dessas regiões como o Moinhos de Vento, a Av. Goethe, a Av. Farrapos, cada uma com uma configuração particular, tanto daquilo que oferece ao público quanto no que se refere ao tipo de público frequentador. Sobre a cidade de Porto Alegre, podem ser citados o trabalho de Dornelles (2004), que foca na vida noturna da Cidade Baixa e da Av. Goethe, e também a dissertação de Fonseca (2006), comparando dois rumos possíveis da noite porto-alegrense, o bairro Moinhos de Vento e a Cidade Baixa.

Mas antes de iniciar a apresentação das minhas observações sobre o bairro acredito ser necessário explicitar as condições nas quais estas foram realizadas. Sou morador do bairro Cidade Baixa há quatro anos e meio, sendo que há um ano e meio minha residência é na Rua João Alfredo, no trecho entre a Rua da República e a Av. Loureiro da Silva. Antes disso, morei por três anos na Av. Loureiro da Silva, conhecida como "Perimetral", entre as ruas Lima e Silva e José do Patrocínio. Residir em um bairro significa circular por ele, vivenciá-lo. E esse período circulando pelas ruas da Cidade Baixa, tanto no cotidiano das caminhadas diárias, das obrigações de trabalho ou a caminho do Campus do Vale da UFRGS, quanto nos momentos de lazer diurno e noturno dentro do próprio bairro, me permitiram atentar para algumas situações que tocam ao universo de pesquisa que venho trabalhando desde a graduação: as práticas de uso de psicoativos.

Desta forma, as observações que serão apresentadas não foram coletadas a partir de um trabalho de campo exaustivo e sim da minha própria vivência no bairro, principalmente das minhas circulações no período noturno, já que sou também um frequentador esporádico de alguns estabelecimentos da região. Além disso, houve algumas ocasiões específicas de observação da rua, do movimento noturno da rua. De qualquer forma, essas observações são de uma experiência espacial muito próxima, cotidiana, havendo a necessidade de um esforço de "estranhamento do familiar", como aponta Velho (2008). Além disso, contei com a colaboração, também de maneira informal e não exaustiva, de pessoas que conheci nesta vivência do bairro: conhecidos, amigos, moradores e/ou frequentadores da Cidade Baixa, cujo relacionamento interpessoal comigo permite que o uso de substâncias psicoativas, lícitas ou ilícitas, seja um assunto permitido, sobre o qual posso fazer indagações e receber respostas. Essas pessoas concordam em identificar este bairro 
como um dos grandes centros de vida noturna de Porto Alegre. Suas saídas noturnas dentro do bairro são caracterizadas pelo consumo de psicoativos, tanto álcool quanto maconha e cocaína, em alguns casos, mas são consumos em grupo, não individualizados. O objetivo é interagir com os amigos, ou mesmo com pessoas desconhecidas nos ambientes frequentados.

As ruas da Cidade Baixa durante as noites, e principalmente nos finais de semana, recebem um conjunto de fluxos intensos, de pessoas e de carros, que não são característicos do bairro em outros períodos do dia e da semana. Silveira (2002), em uma etnografia do cotidiano realizada neste bairro, aponta para as diferenças entre os ritmos durante o dia e durante a noite, sendo o período diurno caracterizado por pessoas a caminho do trabalho ou da escola, moradores passeando com seus animais de estimação, crianças brincando nas calçadas, o comércio variado do bairro funcionando, entre outras atividades. Já o período da noite começa com a abertura dos cafés e bares da região, já no fim das tardes, que recebem uma infinidade de pessoas para conversar, comer, beber, socializar. A Rua Gen. Lima e Silva, a Rua da República e a Rua José do Patrocínio são as principais vias centralizadoras dos bares/restaurantes noturnos, sendo que em alguns trechos das mesmas encontramos um estabelecimento ao lado do outro. Ao mesmo tempo, nessas ruas ainda se preserva um caráter bastante residencial, sendo que muitos bares ocupam os pisos térreos de prédios residenciais.

Com o cair da noite começam a ser ocupadas as casas noturnas da região. Lugares fechados que exigem o pagamento de um ingresso e contam com pista de dança, som mecânico e, em alguns casos, com bandas tocando música ao vivo. Esta vertente da Cidade Baixa se concentra na Rua João Alfredo, sendo que no trecho entre a Rua da República e a Rua Joaquim Nabuco há poucas residências. Esse trecho do bairro é formado principalmente por casas noturnas, situadas em antigas casas residenciais de arquitetura do começo do século XX. Há poucos edifícios residenciais nesta rua.

Os exemplos mais exacerbados desse fenômeno, de uma intensificação e transformação dos fluxos de pessoas no período noturno, são a Rua Gen. Lima e Silva, a Rua da República, a Rua José do Patrocínio, principalmente nas imediações do Bar Opinião, entre as ruas Joaquim Nabuco e Lopo Gonçalves, e a Rua João Alfredo. Essa intensificação permite a formação de circuitos não existentes nesses outros momentos, redes de relações que só são visíveis nos períodos de movimento intenso e de grande aglomeração e circulação de pessoas em alguns pontos. Nesses fluxos intensos criam-se "regiões morais" ou "províncias de significados", que de certa forma apresentam outra abordagem a respeito do uso de substâncias psicoativas ilícitas, diferentes do que normalmente se observa no dia a dia. As esquinas formadas pelo encontro da Rua da República com a Rua João Alfredo, a poucos metros da saída do prédio onde moro, são coincidentemente locais 
privilegiados para se observar as práticas de sociabilidade relacionadas ao uso de psicoativos. Digo coincidentemente porque antes de me mudar para o prédio nunca havia frequentado este trecho da Cidade Baixa durante a noite.

No mapa a seguir é possível observar os limites da Cidade Baixa, entre a Av. João Pessoa, ao leste, e a Av. Praia de Belas, no limite oeste; e entre a Av. Loureiro da Silva, ao norte, e a Av. Aureliano Figueiredo Pinto, ao sul. Em destaque, a localização da minha residência em vermelho. Também destaco na Rua João Alfredo e na Rua José do Patrocínio, em azul, trechos de grande concentração de pessoas na rua, principalmente nas noites de final de semana.

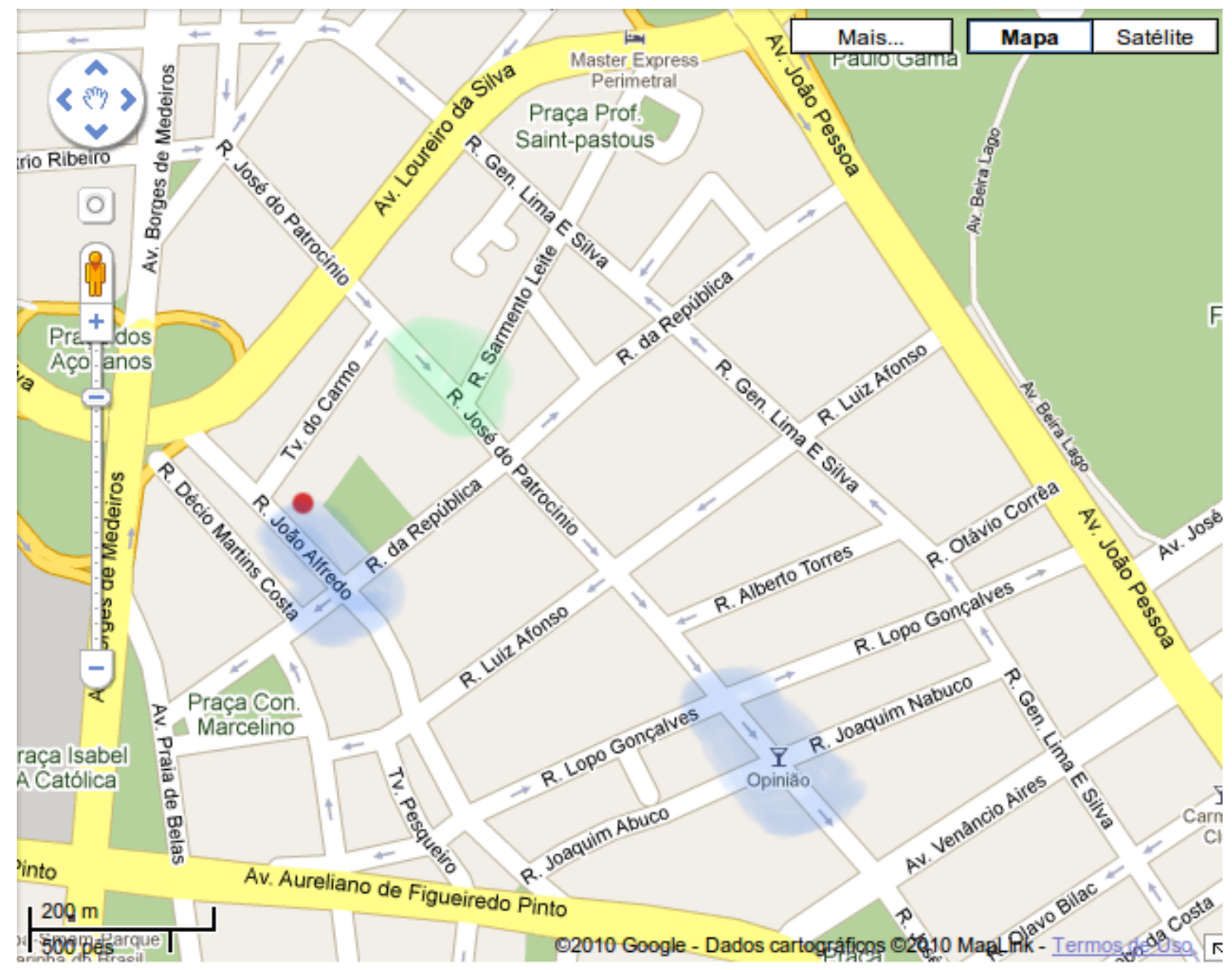

Diferentemente da Rua Gen. Lima e Silva, cuja característica principal é o fluxo, nas regiões destacadas há tanto circulação quanto aglomeração, sendo a aglomeração um fator importante para a sociabilidade particular que se pratica nessas regiões. $\mathrm{O}$ destaque em verde, na esquina da Rua Sarmento Leite com a Rua José do Patrocínio, é para um espaço que até o ano de 2006 proporcionava o mesmo tipo de sociabilidade de rua, ao redor de bares e com interações e sociabilidades próprias, contando com pequeno comércio e consumo observável de substâncias 
psicoativas ilícitas.

É interessante de destacar que as ruas Gen. Lima e Silva e República contam, tanto durante o dia quanto no período noturno, com um fluxo intenso de pessoas e veículos, assim como a própria João Alfredo. O que eu pretendo destacar nas duas áreas manchadas com a cor azul são espaços da rua nos quais alguns fluxos se estabilizam, são espaços nos quais os indivíduos param e sociabilizam, onde há um tipo de aglomeração de pessoas nas calçadas e mesmo na rua. Talvez a explicação para este fenômeno resida no fato de que nesses dois espaços em destaque existem casas noturnas, boates, lugares fechados que exigem o pagamento de um ingresso. Como já foi mencionado, é o caso de praticamente toda a Rua João Alfredo. Mas além desses espaços privados, nas proximidades se localizam bares abertos nos quais os frequentadores compram suas bebidas e usufruem delas, muitas vezes, na própria rua. Nas duas regiões, dentre os bares que circundam as casas noturnas há opções de preços variados, acessíveis a diferentes tipos de públicos. O que se destaca nessas regiões, então, é exatamente essa diversidade, havendo pessoas que estão em circulação, frequentando os bares e casas noturnas, e outras que estão paradas, socializando no meio da multidão. Para estas, a festa, ou o evento de sociabilidade é a própria rua. Em regiões como a Cidade Baixa, de uma vida noturna com grande concentração de pessoas nas ruas, mesmo o uso individualizado de psicoativos pressupõe algum tipo de sociabilidade, pois estar no meio de todas aquelas outras pessoas é uma maneira de se mostrar disposto a interagir.

A mancha verde destacada no mapa remete a um antigo contexto de sociabilidade parecido com as regiões em azul. O trabalho de Silveira (2002) remete a tal esquina como uma possível "boca de fumo" na época de seu trabalho de campo. Das minhas movimentações dentro do bairro, ainda antes de me estabelecer na Rua João Alfredo, lembro que nessa região apontada pelo autor realmente havia uma aglomeração de pessoas nas calçadas da rua José do Patrocínio, que ia desde a esquina com a rua Sarmento Leite até próximo da esquina com a Travessa do Carmo. Neste trecho até hoje existem os mesmos bares frequentados principalmente por um público jovem, mas que agora se restringe aos ambientes fechados, não permanecendo na rua.

Recordo que assim que mudei para Porto Alegre, no primeiro semestre de 2006, essa região foi uma das primeiras que conheci durante a noite, e havia ficado realmente espantado com a aglomeração de pessoas e com o consumo ao ar livre de maconha e cocaína, juntamente com um intenso uso de bebidas alcoólicas. Não apenas consumo, mas comércio explícito das duas substâncias ilegais, com ofertas em voz alta no meio do público. Como era uma situação de claro interesse de pesquisa para mim, ainda que não estivesse diretamente relacionada com meu tema de trabalho na dissertação, muitas vezes conversei com jovens garotos do bairro que ficavam na esquina e se envolviam em pequenas atividades de comércio de substâncias ilícitas. Em um período 
de um ano, nesta mesma esquina, passaram no mínimo quatro "comerciantes" de fora da Cidade Baixa, que vinham para aquela região durante a noite com alguma quantidade de maconha, de cocaína e às vezes de crack. Junto destes, na esquina, ficavam os garotos do bairro, acompanhando e por vezes participando das atividades.

A maconha era consumida na própria rua, em rodas de conhecidos, e a cocaína principalmente nos banheiros dos bares ou então em cantos escuros da região, de maneira bastante discreta. Naquela esquina, várias vezes percebi, pessoas de passagem que paravam exclusivamente para comprar alguma substância, o que caracterizou a região, por algum tempo, realmente como uma "boca de fumo", como um ponto de venda de substâncias ilícitas, o que já não ocorre mais hoje. Os próprios informantes com os quais conversei me identificaram esta esquina como um antigo ponto de venda e consumo de maconha e cocaína.

É uma situação um tanto diferente das outras duas áreas destacadas no mapa em azul, nas quais também acontece um consumo intenso de álcool nas ruas e calçadas, assim como o uso de maconha nas mesmas circunstâncias e também o uso de cocaína em situações não tão explícitas. A diferença é que essas duas regiões não são conhecidas como "pontos de venda" ou "bocas de fumo". Nos fins de semana, pela noite, quando saio do prédio onde moro é muito comum encontrar vários grupos fumando maconha na rua, sem qualquer inibição ou problema, ou então alguém cheirando cocaína dentro de um telefone público ou mesmo dentro de um carro, além das incontáveis pessoas consumindo bebidas alcoólicas. Não parece haver qualquer tipo de constrangimento mútuo entre os consumidores e os não-consumidores de substâncias ilícitas e sim um certo respeito, levando em conta as lógicas próprias daqueles espaços públicos. No trecho da João Alfredo a partir da Rua da República, no sentido sul, fica a grande concentração de casas noturnas e bares fechados, trecho de intensa circulação. Já na parte norte da rua, a partir da República, se concentram as pessoas que ficam paradas, os consumidores de calçada. Essa aglomeração se estende também por parte da Rua da República, tanto a leste quanto a oeste da João Alfredo.

As pessoas com as quais conversei sobre consumo de psicoativos na Cidade Baixa me indicaram que quando estão procurando consumir alguma substância ilícita, mesmo que no próprio bairro, muitas vezes têm de se deslocar a regiões da cidade onde existem reconhecidos "pontos de venda". Fui informado da existência de alguns lugares em zonas de subúrbio e periferia da cidade de Porto Alegre que funcionam como verdadeiros drive-thrus de maconha, cocaína e crack. Locais identificados pelos nomes "Paulina", "Vivi" e "Tuca", acessados com veículos próprios ou então a bordo de táxis que fazem a corrida até esses lugares e voltam ao bairro. Normalmente esses taxistas criam laços de confiança com os clientes que fazem esse tipo de corrida, segundo me informaram, 
pois as viagens podem ser frequentes. Esses lugares, diferentemente da boemia da Cidade Baixa, são caracterizados por residências de classes baixas, nos quais operam exclusivamente as atividades de comércio ilegal, e não há espaço para o consumo ou sociabilidade. O que parece sustentar as lógicas próprias dessas regiões de "boca de fumo" são as estratégias da rede de comércio para se manter em atividade e à disposição dos "clientes".

Esses mesmos informantes me disseram que pode ocorrer períodos em que indivíduos que tem acesso a boas quantidades de alguma substância ilícita frequentem a Cidade Baixa com o intuito de vendê-las, mas que estes não se vinculam a algum espaço físico específico, e sim circulam nos espaços públicos, principalmente nos de grande concentração de pessoas. Assim, fiquei sabendo de um vendedor de cocaína que eventualmente circulava nas proximidades de uma pastelaria do bairro, ou então de outros que circulavam por alguns bares, e assim por diante. Mas são redes restritas, não divulgadas, que são descobertas por pessoas que tem interesse no assunto, não são explicitamente acessíveis a todos, dado o caráter ilegal das atividades praticadas. A Cidade Baixa parece ser uma região da cidade de Porto Alegre com uma grande demanda por substâncias psicoativas, tanto legais quanto ilegais, fato que permite a presença de alguns desses comerciantes de ocasião, que muitas vezes nada tem a ver com os grandes esquemas do macro-tráfico.

Fato é que ao se pensar nos territórios de sociabilidade entorpecida atuantes hoje República X João Alfredo; José do Patrocício nas imediações do Bar Opinião -, e no outro que já não existe mais - José do Patrocício X Sarmento Leite -, pode-se sugerir que na Cidade Baixa ocorra um tipo de "territorialidade itinerante" no que diz respeito a essas "regiões morais" que toleram alguns usos de psicoativos. Esse conceito de território, utilizado recentemente por Frúgoli Jr. \& Spaggiari (2010) para definir a "cracolãndia", em São Paulo, pode ser um instrumento interessante para se pensar o tipo de espaço apresentado neste artigo. Em seu trabalho os autores demonstram como a atuação dos aparatos repressores e de tratamento que incidem sobre os usuários de crack deslocaram os limites territoriais da região conhecida como "cracolândia".

O que esses espaços incitam a pensar, também, é na figura do flâneur, caminhando e deslumbrado com a cidade, perdendo-se no meio da multidão. Incitam a pensar na vivência da rua como espaço de sociabilidade, ainda que aqui estejamos falando de um tipo de sociabilidade bem específico, mediado pelo uso de substâncias psicoativas. Interessante de notar que a atitude do flâneur, à época de Charles Baudelaire, tal qual foi descrita por Benjamim, por si só já conteria um aspecto de entorpecimento:

Uma embriaguez acomete aquele que longamente vagou sem rumo pelas ruas. A cada passo, o andar ganha uma potência crescente; sempre menor se torna a sedução das lojas, dos bistrôs, das mulheres sorridentes e sempre mais irresistível o magnetismo da próxima esquina, de uma massa 
de folhas distantes, de um nome de rua (...) Aquela embriaguez anamnéstica em que vagueia o flâneur pela cidade não se nutre apenas daquilo que, sensorialmente, lhe atinge o olhar; com frequencia também se apossa do simples saber, ou seja, de dados mortos, como de algo experimentado e vivido. (Benjamim, 1994: p.186)

Se pensarmos, então, nessas práticas que agregam a própria flânerie com o uso de psicoativos, que tipo de experiências estarão em jogo, que tipo de conhecimento e vivência da cidade pode-se apreender dessas práticas? São perguntas que por ora não posso responder, mas que incitam a continuação de uma pesquisa empírica mais densa e extensa no interior do universo apresentado neste artigo.

\section{Considerações Finais}

A partir dessas observações fica claro que a Cidade Baixa, como um todo, é uma região privilegiada para se estudar esse tipo de sociabilidade urbana: noturna e mediada pelo uso de substâncias psicoativas. Essas observações iniciais têm a única pretensão de ser um prémapeamento da região, apontando para algumas possibilidades futuras a serem exploradas.

Pensar nas práticas de uso de psicoativos a partir dos referenciais trabalhados aqui incita imediatamente a pensar a própria cidade, em como se constroem, a partir dos deslocamentos dos consumidores pelas várias redes de pessoas e objetos, essas diferentes "províncias de significado" ou "regiões morais" que configuram o mundo urbano contemporâneo. O exercício proposto neste artigo foi apresentar observações sobre um tipo de espaço público que congrega uma diversidade de pessoas e grupos de pessoas em atividades de sociabilidade e entorpecimento, e também que estas práticas de entorpecimento podem ser interpretadas de maneira positiva a partir da ideia de "hábito". Mas isso não quer dizer que todas as pessoas presentes nessas regiões compartilhem muito mais do que o espaço físico. Procurei identificar dentro do bairro Cidade Baixa alguns espaços de convergência de deslocamentos que resultam em situações de sociabilidade. Os ritmos da cidade proporcionam tipos específicos de sociabilidade em determinados momentos e espaços, como nos exemplos apresentados neste artigo.

Não obstante, a referência espacial dessas sociabilidades mediadas pelo uso de psicoativos parece ser muito importante. A própria memória, individual e/ou coletiva, de certa forma está associada a espaços, a lugares, e no caso do uso de psicoativos não poderia deixar de ser diferente. Posso afirmá-lo a partir de dados obtidos durante a realização de minha pesquisa para o mestrado, junto a grupos de Narcóticos Anônimos (Loeck, 2009). Para os dependentes em recuperação neste tipo de grupo de ajuda mútua, que pauta sua proposta terapêutica na abstinência total do uso de qualquer substância psicoativa, há a sugestão para que os participantes evitem "lugares, hábitos e pessoas" da época em que faziam uso de substâncias. A ideia por trás dessa sugestão é de que essas 
atividades são, realmente, práticas de sociabilidade, práticas associadas a pessoas e lugares, não necessariamente práticas individualizadas. Desta forma, evitando pessoas ou lugares que sabidamente estão associados ao uso de psicoativos, esses indivíduos em recuperação estarão evitando a própria memória do uso, que impulsiona a emergência de hábitos que devem ser evitados.

Finalmente, penso que os referenciais trabalhados neste artigo possuem grande potencial para se pensar as práticas de uso de substâncias psicoativas no mundo urbano contemporâneo, na medida em que fogem das definições biomédicas e legalistas que muitas vezes se sobrepõem a outras interpretações no caso das substâncias ilícitas.

\section{Referências}

BACHELARD, G. L'intuition de l'instant. Paris: Denoel, 1965.

BECKER, H. S. "Becoming a Marijuana user". In: Outsiders: Studies in the Sociology of Deviance. Nova Iorque: The Free Press, 1973.

BENJAMIM, W. Charles Baudelaire: um lírico no auge do capitalismo - Obras escolhidas, v. III. São Paulo: Ed. Brasiliense, 1994.

BERGSON, H. Ensaio sobre os dados imediatos da consciência. Lisboa: Edições 70, 1988.

CARLINI, E. A. (supervisão) [et. al.]. II Levantamento domiciliar sobre o uso de drogas psicotrópicas no Brasil: estudo envolvendo as 108 maiores cidades do país: 2005. São Paulo: UNIFESP/ CEBRID - Centro Brasileiro de Informação sobre Drogas Psicotrópicas, 2006.

CARNEIRO, H. A fabricação do vício. Núcleo de Estudos Interdisciplinares sobre Psicoativos (NEIP), 2002. Disponível em: <www.neip.info>. Acessado em outubro de 2010.

Pequena enciclopédia da história das drogas e bebidas. Rio de Janeiro: Campus/Elsevier, 2005.

. "Autonomia ou heteronomia nos estados alterados de consciência". In: LABATE, B. C.; GOUlART, S.; FIORE, M.; MACRAE, E.; CARNEIRO, H. (orgs.). Drogas e Culturas: novas perspectivas. Salvador: EDUFBA, 2008. p.65-90.

DORNELLES, J. "O encontro entre "Goethe" e "Lima e Silva"". In: Iluminuras, v. 5, n. 10. Porto Alegre: BIEV/ UFRGS, 2004.

ECKERT, C.; ROCHA, A. L. C. "Premissas para o estudo da memória coletiva no mundo urbano contemporâneo sob ótica dos itinerários de grupos urbanos e suas formas de sociabilidade". In: Iluminuras, v. 2, n. 4. Porto Alegre: BIEV/ UFRGS, 2001.

FERNANDEZ, O. Coca Light? Usos do Corpo, Rituais de Consumo e Carreiras de Cheiradores de cocaína em São Paulo. 2007. Tese (Doutorado em Ciências Sociais - Antropologia) - Universidade Federal da Bahia, 2007.

FONSECA, L. M. Dois rumos na noite de Porto Alegre: Dinâmica socioespacial e lazer urbano nos bairros Cidade Baixa e Moinhos de Vento. 2006. Dissertação (Mestrado em Planejamento Urbano e Regional) - Programa de Pós-Graduação em Planejamento Urbano e Regional, Universidade Federal do Rio Grande do Sul, 2006.

FOUCAULT, M. História da Sexualidade I: a vontade de saber. Rio de Janeiro: Graal, 1982.

FRÚGOLI JR., H.; SPAGGIARI, E. "Da cracolãndia aos nóias: percursos etnográficos no bairro da Luz". In: PontoUrbe: Revista do Núcleo de Antropologia Urbana da USP. Ano 4, Versão 6.0, Agosto de 2010. Disponível on-line em: <http://www.pontourbe.net/edicao6-artigos/118-dacracolandia-aos-noias-percursos-etnograficos-no-bairro-da-luz $>$. Acessado em Outubro de 2010. 
GOFFMAN, E. Estigma. Notas sobre a manipulação da identidade deteriorada. Rio de Janeiro: Zahar, 1975.

JARDIM. D. F. De bar em bar: identidade masculina e auto-segregação entre homens de classes populares. Dissertação (Mestrado em Antropologia Social) - Programa de Pós-Graduação em Antropologia Social, Universidade Federal do Rio Grande do Sul, 2006 [1991].

LOECK, J. F. Adicção e Ajuda Mútua: Estudo Antropológico de Grupos de Narcóticos Anônimos na cidade de Porto Alegre (RS). Dissertação (Mestrado em Antropologia Social) - Programa de Pós-Graduação em Antropologia Social, Universidade Federal do Rio Grande do Sul, 2009.

MACRAE, E. \& SIMÔES, J. A. Rodas de fumo: O uso de maconha entre camadas médias urbanas. Salvador: EDUFBA, 2000.

SILVEIRA, F. L. A. da. "A poética do vivido: uma etnografia do cotidiano na Cidade Baixa POA/RS”. In: Iluminuras, v. 3, n. 5. Porto Alegre: BIEV/ UFRGS, 2002.

SIMMEL, G. Sociologia. São Paulo: Ática, 1983.

STENGERS, I. "Drugs: Ethical Choice or Moral Consensus". In.: Power and Invention: Situating Science. Minneapolis: University of Minnesota Press, 1997.

VARGAS, E. V. "Uso de drogas: a alter-ação como evento". In: Revista de Antropologia, v. 49. São Paulo: USP, 2006. p. 581-623.

. "Fármacos e outros objetos sócio-técnicos: notas para uma genealogia das drogas". In:

LABATE, B. C.; GOUlART, S.; FIORE, M.; MACRAE, E.; CARNEIRO, H. (orgs.). Drogas $e$ Culturas: novas perspectivas. Salvador: EDUFBA, 2008. p.41-63.

VELHO, G. Nobres e Anjos: Um estudo de tóxicos e hierarquia. Rio de Janeiro: FGV, 1998. Observando o Familiar. In: Individualismo e cultura: notas para uma antropologia da sociedade contemporânea. Rio de Janeiro: Zahar, 2008.

Recebido em: 21/12/2010

Aprovado em: 28/03/2011 